\title{
Screening mammography use in older women according to health status: a systematic review and meta-analysis
}

\author{
This article was published in the following Dove Press journal: \\ Clinical Interventions in Aging
}

\author{
Joshua Demb 1,2 \\ Tomi Akinyemiju ${ }^{3}$ \\ Isabel Allen' \\ Tracy Onega ${ }^{4}$ \\ Robert A Hiatt' \\ Dejana Braithwaite ${ }^{2}$ \\ 'Department of Epidemiology and \\ Biostatistics, University of California, \\ San Francisco, CA, USA; ${ }^{2}$ Department \\ of Oncology, Georgetown University \\ School of Medicine, Washington, DC, \\ USA; ${ }^{3}$ Department of Epidemiology, \\ University of Kentucky, Lexington, KY, \\ USA; ${ }^{4}$ Department of Biomedical Data \\ Science, Geisel School of Medicine at \\ Dartmouth, Hanover, NH, USA
}

Correspondence: Dejana Braithwaite Department of Oncology, Georgetown University School of Medicine, 3300 Whitehaven Street Northwest, Suite 4100 , Harris Building, Washington, DC 20007-240I, USA

Tel +I 2026870802

Email dejana.braithwaite@ georgetown.edu
Background: The extent to which screening mammography (SM) recommendations in older women incorporate life expectancy factors is not well established.

Objective: The objective of this review was to evaluate evidence on SM utilization in older women by life expectancy factors.

Data sources: We searched Medline, Embase and Web of Science from January 1991 to March 2016.

Study selection: We included studies examining SM utilization in women ages $\geq 65$ years that measured life expectancy using comorbidity, functional limitations or health or prognostic status.

Data extraction and synthesis: ORs and 95\% CIs were extracted and grouped by life expectancy category. Findings were aggregated into pooled ORs and 95\% CIs and meta-analyzed by life expectancy category.

Main outcomes and measures: The primary outcome was SM utilization within the last 5 years. Life expectancy factors included number of comorbidities, Charlson Comorbidity Index (CCI), activities of daily living, instrumental activities of daily living, self-reported health status and 5-year prognostic indices.

Results: Of 2,606 potential titles, we identified 25 meeting the inclusion criteria (comorbidity: eight studies, functional status: 11 studies and health/prognostic status: 13 studies). Women with higher CCI scores had decreased SM utilization (pooled OR: 0.75, 95\% CI: 0.67-0.85), but increased absolute number of comorbidities were weakly associated with increased SM utilization (pooled OR: 1.17, 95\% CI: 1.00-1.36). Women with more functional limitations had lower SM use odds than women with no limitations (pooled OR: 0.72, 95\% CI: 0.62-0.83). Screening utilization odds were lower among women with poor vs excellent health (pooled OR: $0.85,95 \%$ CI: 0.74-0.96).

Conclusion: Greater CCI score, functional limitations and lower perceived health were associated with decreased SM use, whereas higher absolute number of comorbidities was associated with increased SM use. SM guidelines should consider these factors to improve assessments of potential benefits and harms in older women.

Keywords: screening mammography, comorbidity, functional limitations, health status, meta-analysis

\section{Introduction}

More than $50 \%$ of new invasive breast cancer cases diagnosed each year in the US occur among older women - women ages 65 years or older. ${ }^{1}$ The increasing life expectancy of women in the US and attendant rise in the absolute number of breast cancer cases in older women will likely lead to an increasing absolute number of 
mammograms performed in the $\geq 65$ age group. $^{2}$ In 2010 , the United States Centers for Disease Control and Prevention estimated that older women reported the highest prevalence of mammography use within the past 2 years. ${ }^{3}$ However, the US Preventive Services Task Force (USPSTF) currently does not recommend screening mammography (SM) in women ages 75 or older due to insufficient evidence. ${ }^{4}$ Although older women have a higher risk of breast cancer and lower risk of false-positive mammography results than younger women, their shorter life expectancy decreases the potential benefits of screening. ${ }^{4-6}$

A recent review concluded that screening for breast cancer is most appropriate for women with a life expectancy of at least 10 years. ${ }^{7}$ Because the full benefit of screening is only realized with reduction in mortality, numerous studies have accounted for life expectancy factors to better identify the margin of benefit a woman might expect from undergoing screening. ${ }^{3,7-10}$ To date, comorbidity burden, functional status and self-reported heath are the strongest predictors of life expectancy. ${ }^{11-14}$ However, the current guidelines for SM do not account for life expectancy factors other than chronological age. ${ }^{4,15}$

In light of the current demographic, epidemiologic and policy environment, it is important to understand the extent to which the current practice of SM is targeted to healthy older women and avoided in older women with limited life expectancy. In this review, we reported the results of a systematic review and meta-analysis of the literature of studies assessing mammography screening utilization rates of older women in relation to age, functional limitations and health status including but not limited to comorbidity. The main objective of this review was to outline the current practices that exist for SM utilization in older women and the association between screening and life expectancy factors in order to help guide future SM guidelines.

\section{Methods}

This systematic review and meta-analysis has a published protocol $^{16}$ and is registered with PROSPERO with the registration number CRD42016032661. A PRISMA checklist is included in Table S1. The study is covered under an institutional review board (IRB) with exempt status submitted and approved by the IRB of University of California, San Francisco.

\section{Search strategy and selection criteria}

We performed a systematic search of the literature using Medline (using PubMed interface), Embase and Web of Science (January 1, 1991-March 1, 2016) to identify relevant studies. "Breast neoplasms" was combined with the permutations, variations and abbreviations of the relevant Medical Subject Headings (MeSH) keywords and non-MeSH key terms for mammography, age, health status and comorbidity, including cardiovascular diseases, comorbidity, cognition disorders, diabetes mellitus, functional limitation, health status, myocardial infarction and stroke. Complete search strategies are provided in the "Supplementary materials" section.

The broad criteria for this review allowed for the evaluation of multiple study designs published in English. The inclusion criteria were as follows: i) women aged 65 years or older in the US, ii) assessment of women's comorbidity (either as a specific condition or as a summary score), functional impairments and/or health status and iii) an outcome measure that addresses recent SM utilization. Additional studies were obtained through citations of review articles or contacting breast cancer screening experts regarding any unpublished articles that may be suitable for inclusion in the systematic review. Case reports were excluded. Data were extracted from the full-text article.

Most, if not all, of the target population was Medicare beneficiaries, with SM covered based on policy changes implemented in 1991. ${ }^{17}$ At that time, Medicare Part B medical insurance, for which most women become eligible when they turn 65 years, covered the full cost of annual mammography for all women aged 40 or older. ${ }^{2,4}$ To account for this Medicare policy change, we excluded studies evaluating screening utilization prior to $1991 .{ }^{17}$ Women eligible for Medicare ages 65-74 years are near the upper limit of the USPSTF primary SM guidelines (age 74 years), and USPSTF guidelines note that data are currently inconclusive to provide screening recommendations for women ages 75 or older. ${ }^{18}$

\section{Quality assessment and data extraction}

To evaluate the quality of included studies, we used the Newcastle-Ottawa Scale (NOS) and Cochrane Collaboration Risk of Bias (CCRB) tool ${ }^{19,20}$ to evaluate observational studies and clinical trials, respectively. The NOS measures the methodological quality of observational studies, giving predefined criteria, some of which have to be further specified based on topic. We specified these criteria in a consensus meeting with the authors (Tables S2A and S2B) before assessing the studies.

Studies were assessed for quality of selection (representativeness, selection of controls, ascertainment of exposure), comparability (adjustment for confounding) and outcome or exposure (assessment of outcome/exposure, length and adequacy of follow-up) independently by two authors (JD and TA). Measures of age, socioeconomic status (such as 
race, education, income), health insurance and number of physician visits were identified as important confounders. Cohort and case-control studies could earn a maximum of 9 points, and cross-sectional and randomized clinical trials could earn a maximum of 10 points. Studies with scores of 6-8 points were considered to be of moderate-to-good study quality, and scores of $\geq 9$ were deemed excellent. All studies were summarized irrespective of quality score.

A data extraction form was used to collect study characteristics, including type of study, number of participants, length of follow-up, exposure(s), outcome(s) and quality assessment. Exposures logged in this form were life expectancy factors, including comorbidity scales or specific diseases considered, functional limitation scales used and measures of health status. The primary outcome was SM utilization, defined as SM occurring within the last 1-5 years. We extracted ORs and corresponding 95\% CIs from most studies, with some studies providing risk ratios or proportions of utilization. Quantitative results were extracted from text and tables, choosing preferably those adjusted for important confounders. Two authors (JD and TA) independently performed study quality assessment and data extraction. Discrepancies were discussed and resolved by the review team.

\section{Qualitative synthesis and meta-analysis}

We conducted a qualitative synthesis to describe the findings of included studies, explore associations of interest and examine the quality of the studies and robustness of the systematic review. Study findings were separated into the four exposure categories: comorbidity (measured using an absolute count, Charlson Comorbidity Index [CCI] and individual disease conditions), functional limitations (activities of daily living [ADLs], instrumental activities of daily living [IADLs]), health status and prognostic status. For each exposure, we aggregated study findings to perform metaanalyses assessing the overall magnitude of the association with recent SM utilization. Pooled ORs and corresponding 95\% CIs were reported. Given the variation in measurement of exposures, we stratified our findings to address study heterogeneity. Heterogeneity was measured using $I^{2}$ values and Cochran's $Q$ statistic. Pooled results were analyzed using random-effects models to control for heterogeneity.

We also performed sensitivity analyses to examine potential publication bias including jackknife analyse ${ }^{21}$ and reported these findings in addition to the primary study findings and subgroup analyses. ${ }^{22} \mathrm{We}$ also performed meta-regression to understand how study traits contributed to heterogeneity of pooled effect estimates. ${ }^{23,24}$ The meta-analysis results are graphically displayed using forest plots. ${ }^{22}$ All analyses were performed using STATA 13 (StataCorp LP, College Station, TX, USA).

\section{Results}

Study characteristics, including number of subjects, age range, years of data accrual, study design, assessment of outcome and assessment of exposure, are summarized in Table 1. We tabulated the full Newcastle-Ottawa findings of individual studies for descriptive purposes (Tables S2A and $\underline{\mathrm{S} 2 \mathrm{~B}}$ ). Full descriptive results by exposure type are found in Tables S3- 5 .

\section{Literature search}

We identified 2,606 potentially relevant titles through PubMed, Embase and Web of Science (refer PRISMA flowchart in Figure 1). After excluding titles that did not report i) SM utilization and ii) comorbidity, health status and/or functional status and iii) original research that did not include (d) populations from the US, (e) SM utilization prior to 1991 and (f) results for women $<65$ years old, we identified 142 studies published between January 1, 1991, and March 31, 2016. After review of abstracts, we excluded 95 articles that did not meet the inclusion criteria. After reviewing 47 full-text articles, ${ }^{17,25-70} 25$ studies were included in the review, published between 1996 and 2016: there were ten cohort studies $^{29,31,32,39,40,42,56,63,64,68}$ and 15 cross-sectional studies. ${ }^{17,27}$, 33,36,37,44,46,51,52,59-62,65,69 No case-control studies were found, which is likely due to the highly common outcome of screening utilization. Characteristics of included studies are given in Table 1. Since three studies did not include ORs, only 22 of the 25 studies were included in the meta-analysis.

\section{Quality assessment}

All of the studies used a combination of surveys, Medicare insurance claims data and/or medical records to examine associations between the predictor(s) - comorbidity, functional status or health status - and the outcome, mammography utilization. Based on the quality assessment using the NOS (no clinical trials were included), ${ }^{19}$ all studies were found to be of moderate to excellent quality, despite several studies using self-reported outcome assessment.

\section{Estimates of the effect of the comorbidity on utilization of SM}

A full list of comorbidities measured in each study can be found in Table S3A-C. Eight studies measured the association of comorbidity with SM utilization, with four studies using an unweighted number of comorbid 
Table I Characteristics of studies identified in literature search

\begin{tabular}{|c|c|c|c|c|c|c|c|}
\hline Source & $\begin{array}{l}\text { Number of } \\
\text { subjects }\end{array}$ & $\begin{array}{l}\text { Age range, } \\
\text { years }\end{array}$ & $\begin{array}{l}\text { Accrual } \\
\text { years }\end{array}$ & Study design & $\begin{array}{l}\text { Assessment of } \\
\text { comorbidity/functional } \\
\text { status/health status }\end{array}$ & $\begin{array}{l}\text { Assessment of } \\
\text { mammography } \\
\text { utilization }\end{array}$ & Outcome(s) \\
\hline Ives et $\mathrm{al}^{42}$ & 2,175 & $65-79$ & $199 \mid-1992$ & $\begin{array}{l}\text { Cohort } \\
\text { (prospective) }\end{array}$ & Medicare claims & Medicare claims & $\begin{array}{l}\geq 1 \text { screening } \\
\text { in } 2 \text { years }\end{array}$ \\
\hline Kiefe et a ${ }^{14}$ & $\mathrm{I}, 764$ & $\geq 50$ & 1995 & Cross-sectional & Medical records review & $\begin{array}{l}\text { Medical records } \\
\text { review }\end{array}$ & $\begin{array}{l}\geq 1 \text { screening } \\
\text { within } 2 \text { years }\end{array}$ \\
\hline Blustein et a ${ }^{29}$ & 2,352 & $\geq 75$ & $|99|-1992$ & $\begin{array}{l}\text { Cohort } \\
\text { (retrospective) }\end{array}$ & Self-reported & Medicare claims & $\begin{array}{l}\geq 1 \text { screening } \\
\text { within } 2 \text { years }\end{array}$ \\
\hline Wright et al ${ }^{69}$ & 526 & $\geq 70$ & $1992-1993$ & Cross-sectional & Self-reported & Self-reported & $\begin{array}{l}\geq \mathrm{I} \text { screening } \\
\text { within } 2 \text { years }\end{array}$ \\
\hline Barr et $\mathrm{al}^{27}$ & 309 & $\geq 65$ & 2000 & Cross-sectional & Self-reported & Self-reported & $\begin{array}{l}\geq 1 \text { screening } \\
\text { within } 2 \text { years }\end{array}$ \\
\hline Scinto et $\mathrm{a}^{63}$ & 844 & $\geq 65$ & $1990-1995$ & $\begin{array}{l}\text { Cohort } \\
\text { (prospective) }\end{array}$ & $\begin{array}{l}\text { Self-reported, Medicare } \\
\text { claims }\end{array}$ & Medicare claims & $\begin{array}{l}\geq 1 \text { screening } \\
\text { within } 5 \text { years }\end{array}$ \\
\hline Caplan ${ }^{33}$ & - & $\begin{array}{l}50-69 \\
\geq 70\end{array}$ & $\begin{array}{l}1991-1992 \\
1997-1998\end{array}$ & Cross-sectional & Self-reported & Self-reported & $\begin{array}{l}\geq 1 \text { screening } \\
\text { within } 2 \text { years }\end{array}$ \\
\hline Heflin et $\mathrm{al}^{37}$ & 2,225 & $\geq 65$ & 1992 & Cross-sectional & Self-reported & Self-reported & $\begin{array}{l}\geq 1 \text { screening } \\
\text { within } 2 \text { years }\end{array}$ \\
\hline Harrison et al ${ }^{36}$ & 10,000 & $\geq 65$ & $1993-1997$ & Cross-sectional & Medicare claims & Medicare claims & $\begin{array}{l}\geq \mathrm{I} \text { screening } \\
\text { within } 5 \text { years }\end{array}$ \\
\hline $\begin{array}{l}\text { Schootman and } \\
\text { Jeffe }\end{array}$ & 4,477 & $\geq 40$ & 1996 & Cross-sectional & Self-reported & Self-reported & $\begin{array}{l}\geq \text { I screening } \\
\text { within I year }\end{array}$ \\
\hline Schonberg et a ${ }^{59}$ & 882 & $\geq 80$ & 2000 & Cross-sectional & Self-reported & Self-reported & $\begin{array}{l}\geq 1 \text { screening } \\
\text { within } 2 \text { years }\end{array}$ \\
\hline Walter et al ${ }^{17}$ & 3,988 & $\geq 70$ & $2000-2001$ & Cross-sectional & Self-reported & Self-reported & $\begin{array}{l}\geq 1 \text { screening } \\
\text { within } 2 \text { years }\end{array}$ \\
\hline Bynum et $\mathrm{al}^{31}$ & 722,310 & $\geq 65$ & $2000-2001$ & $\begin{array}{l}\text { Cohort } \\
\text { (retrospective) }\end{array}$ & Medicare claims & Medicare claims & $\begin{array}{l}\geq 1 \text { screening } \\
\text { within } 2 \text { years }\end{array}$ \\
\hline Holt et $\mathrm{al}^{39}$ & 5,461 & $\geq 65$ & $1998-2002$ & $\begin{array}{l}\text { Cohort } \\
\text { (retrospective) }\end{array}$ & Self-reported & $\begin{array}{l}\text { Self-reported, } \\
\text { Medicare claims }\end{array}$ & $\begin{array}{l}\geq \text { I screening } \\
\text { within I year }\end{array}$ \\
\hline Thorpe et $\mathrm{al}^{65}$ & 3,655 & $\geq 65$ & $|999-200|$ & Cross-sectional & Self-reported & Self-reported & $\begin{array}{l}\geq 1 \text { screening } \\
\text { within } 2 \text { years }\end{array}$ \\
\hline Mcbean and $\mathrm{Yu}^{51}$ & 99,438 & $\geq 65$ & 1997-1998 & Cross-sectional & Medicare claims & Medicare claims & $\begin{array}{l}\geq 1 \text { screening } \\
\text { within } 2 \text { years }\end{array}$ \\
\hline Schonberg et $\mathrm{a}^{|6|}$ & 4,683 & $\geq 65$ & 2005 & Cross-sectional & Self-reported & Self-reported & $\begin{array}{l}\geq 1 \text { screening } \\
\text { within } 2 \text { years }\end{array}$ \\
\hline Williams et $\mathrm{al}^{68}$ & 4,222 & $\geq 65$ & $2002-2004$ & $\begin{array}{l}\text { Cohort } \\
\text { (retrospective) }\end{array}$ & Validated measures & Self-reported & $\begin{array}{l}\geq 1 \text { screening } \\
\text { within } 2 \text { years }\end{array}$ \\
\hline Mehta et $\mathrm{a}^{52}$ & 4,312 & $\geq 70$ & 2002 & Cross-sectional & Interview & Medicare claims & $\begin{array}{l}\geq 1 \text { screening } \\
\text { within } 2 \text { years }\end{array}$ \\
\hline Caban et $\mathrm{a}^{32}$ & 4,610 & $\geq 65$ & 2004-2005 & $\begin{array}{l}\text { Cohort } \\
\text { (retrospective) }\end{array}$ & Self-reported & Self-reported & $\begin{array}{l}\geq \text { I screening } \\
\text { within I year }\end{array}$ \\
\hline $\begin{array}{l}\text { Reyes-Ortiz } \\
\text { et al }{ }^{56}\end{array}$ & 1,272 & $\geq 75$ & 2004-2005 & $\begin{array}{l}\text { Cohort } \\
\text { (retrospective) }\end{array}$ & Self-reported & Self-reported & $\begin{array}{l}\geq 1 \text { screening } \\
\text { within } 2 \text { years }\end{array}$ \\
\hline Koya et $\mathrm{al}^{46}$ & 4,836 & $\geq 65$ & 2002 & Cross-sectional & Self-reported & Self-reported & $\begin{array}{l}\geq \text { I screening } \\
\text { within I year }\end{array}$ \\
\hline Tan et $\mathrm{al}^{64}$ & 716,279 & $\geq 75$ & $2006-2007$ & $\begin{array}{l}\text { Cohort } \\
\text { (retrospective) }\end{array}$ & Medical record, claims & Medicare claims & $\begin{array}{l}\geq 1 \text { screening } \\
\text { within } 2 \text { years }\end{array}$ \\
\hline Schonberg et a ${ }^{60}$ & 2,266 & $\geq 75$ & 2008,2010 & Cross-sectional & Self-reported & Self-reported & $\begin{array}{l}\geq 1 \text { screening } \\
\text { within } 2 \text { years }\end{array}$ \\
\hline Hubbard et al ${ }^{40}$ & 49,775 & $\leq 65$ & $2005-2010$ & $\begin{array}{l}\text { Cohort } \\
\text { (retrospective) }\end{array}$ & Medicare claims & Medicare claims & $\begin{array}{l}\geq 1 \text { screening } \\
\text { within } 2 \text { years }\end{array}$ \\
\hline
\end{tabular}

conditions' measure ${ }^{32,37,59,71}$ and four studies using the CCI (Figure 2). ${ }^{44,51,64,69}$ The pooled result showed no significant association between comorbidity and SM utilization (OR: 0.94, 95\% CI: 0.80-1.10). However, when stratified by comorbidity measurement, increased comorbidity measured using CCI was associated with decreased SM utilization (OR: 0.75, 95\% CI: 0.67-0.85), while increased absolute number of comorbidities was weakly associated with 

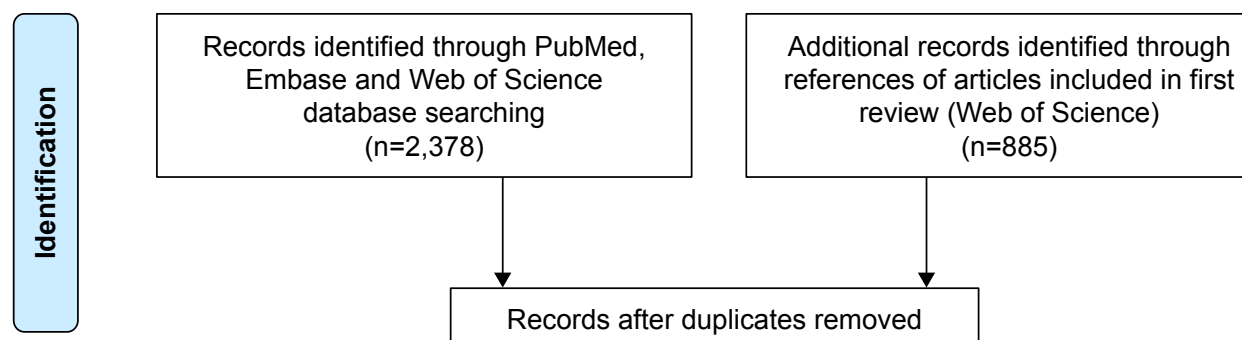

Additional records identified through

references of articles included in first review (Web of Science) $(n=2,378)$
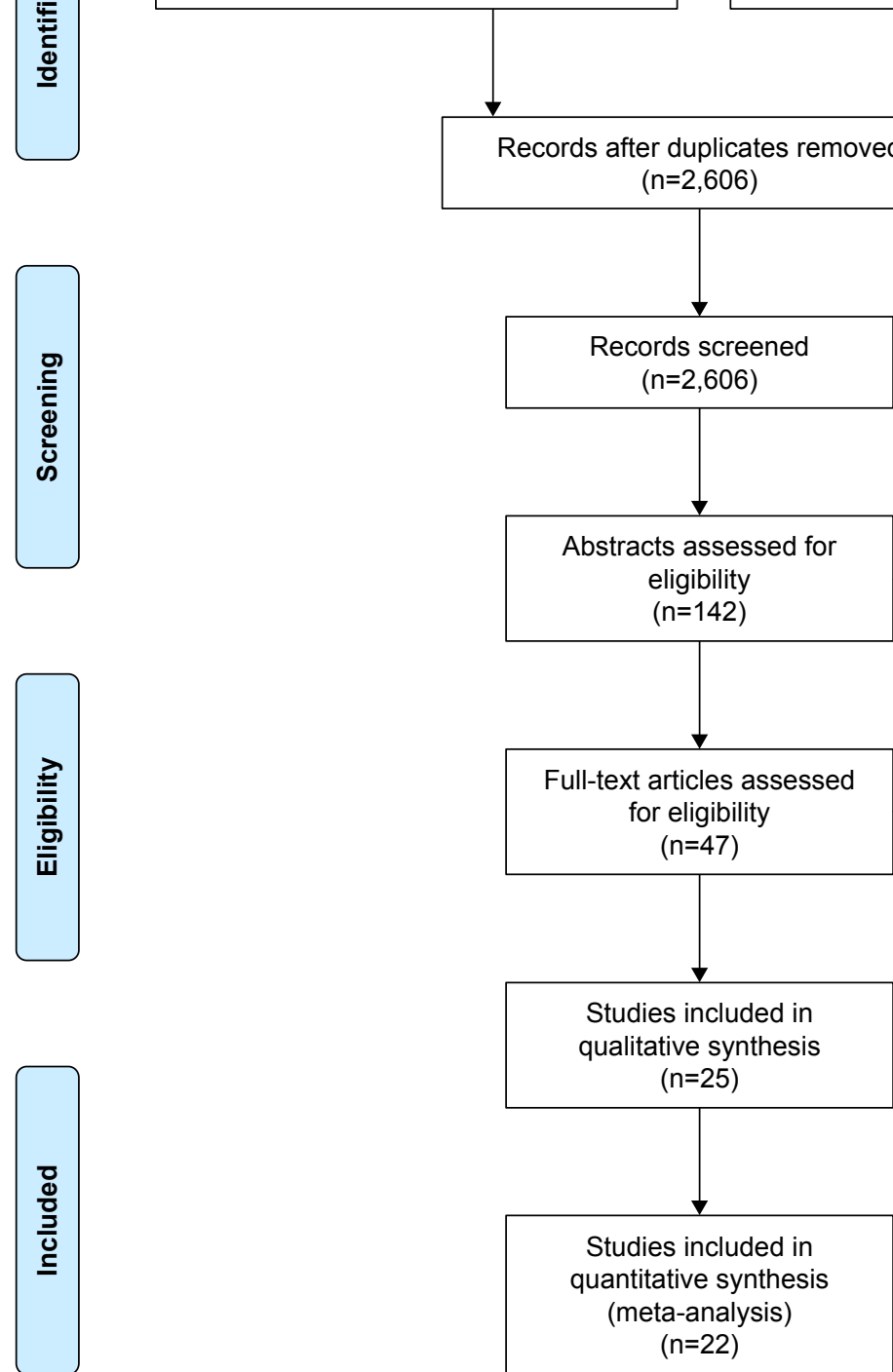
$(n=885)$

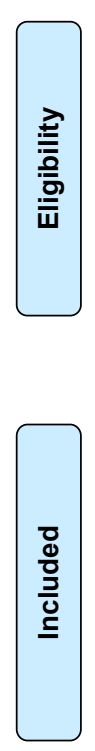

Records excluded $(n=2,464)$

- Title review indicated irrelevance

Abstracts excluded, with reasons $(n=95)$

- Screening mammography was not the outcome $(n=48)$

- Did not measure comorbidity, functional status or health status $(n=22)$

- Age group did not include women ages $\geq 65$ years $(n=20)$

- Contained no analysis $(n=5)$

Figure I PRISMA flowchart of studies included.

Note: Copyright: @ 2009 Moher et al. Moher D, Liberati A, Tetzlaff J, Altman DG, The PRISMA Group (2009). Preferred reporting items for systematic reviews and metaanalyses: the PRISMA statement. PLoS Med 6(7):e1000097. doi: 10.137I/journal.pmed I 000097.

increased SM utilization (OR: 1.17, 95\% CI: 1.00-1.36). Meta-regression results indicated that studies measuring comorbidity using CCI showed significantly lower SM utilization (pooled OR: 0.64, 95\% CI: 0.50-0.82). Jackknife analyses showed that removal of McBean et al's study and the 2004 Schonberg et al's study, the two studies with the most extreme results, from CCI and absolute number of comorbidities groups, respectively, led to insignificant decreases in study heterogeneity and no marked change in the summary estimates.

In addition, nine studies measured individual comorbid conditions and their association with SM utilization
(Table S3C). ${ }^{29,32,38,42,44,52,56,60,65}$ Physical conditions measured included hypertension, diabetes, lung disease, cancer, arthritis, myocardial infarction, stroke, heart disease and hip fracture. Mental conditions measured included cognitive impairment, Alzheimer's disease, depression and psychological distress. In pooled analyses, individual comorbid conditions were not significantly associated with SM utilization (OR: 0.97, 95\% CI: 0.89-1.06; Figure S1). When stratified by type of condition, neither physical conditions (OR: 1.03, 95\% CI: 0.93-1.14) nor mental conditions (OR: 0.85, 95\% CI: 0.72-1.01) were significantly associated with SM utilization. 


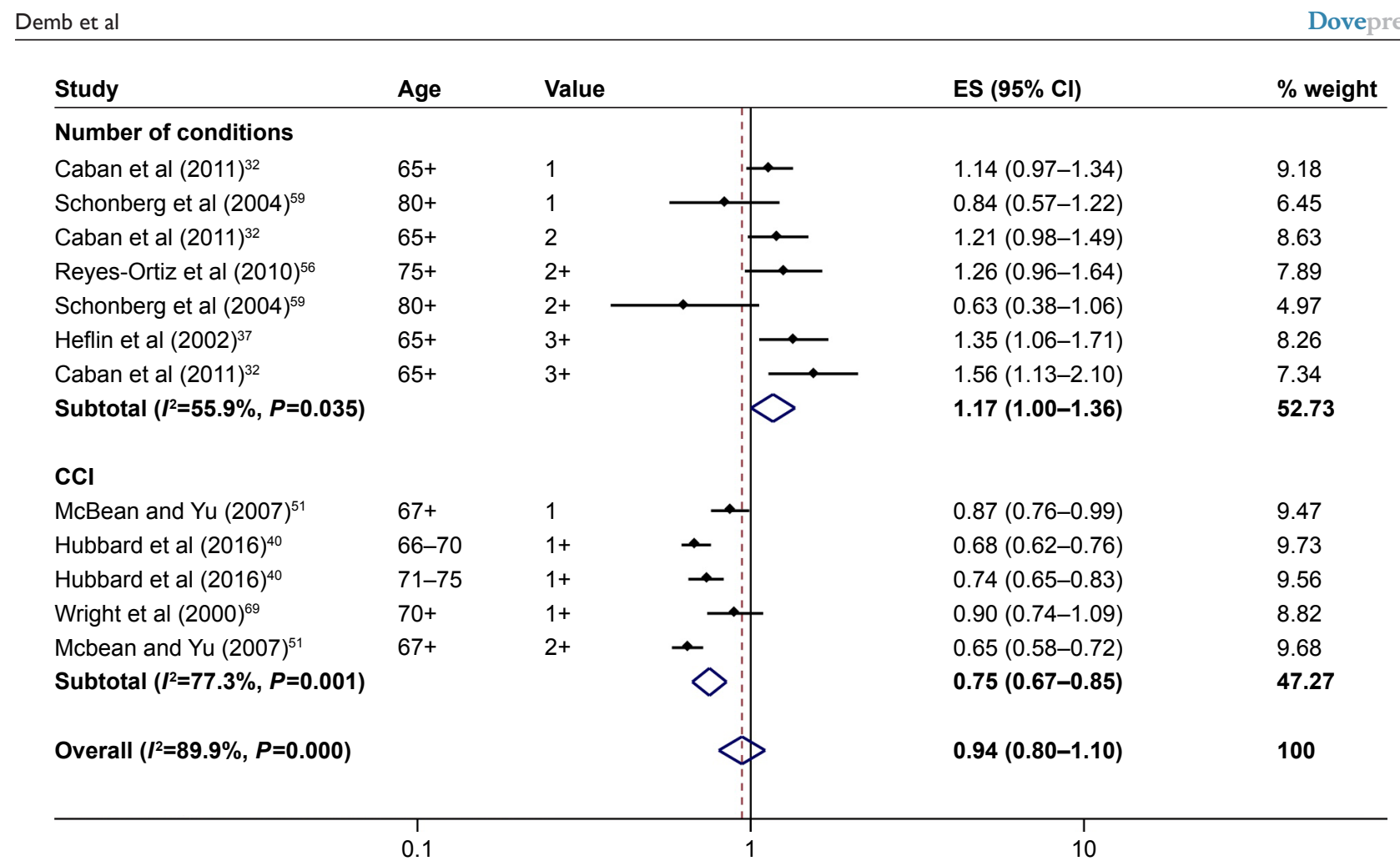

Figure 2 Forest plot of effect of comorbidity on SM utilization by study and measure type.

Note: Weights are from random-effects analysis.

Abbreviations: SM, screening mammography; ES, effect size; $\mathrm{CCl}$, Charlson Comorbidity Index.

\section{Estimates of the effect of functional status on utilization of SM}

Ten studies measured the effect of functional limitations on SM utilization (Figure 3), with three studies measuring functional limitations in multiple ways. Five studies measured ADLs, ${ }^{29,33,42,62,63}$ five studies measured IADLs ${ }^{32,37,42,56,59}$ and three studies used a scale incorporating both IADLs and ADLs. ${ }^{32,59,69}$ Overall, functional limitations were associated with decreased SM utilization (pooled OR: 0.72, 95\% CI: 0.62-0.83). Of the five studies measuring ADLs, three calculated ORs, showing a significant pooled effect of higher number of ADLs on decreased SM utilization (pooled OR: $0.55,95 \%$ CI: $0.35-0.85)$ in Figure 3. Two studies reported chi-square results comparing SM utilization by ADL status (yes/no), with both studies showing a significant difference in screening utilization among women experiencing ADL limitations compared to women with no ADL limitations. ${ }^{33,63}$

Among the four studies measuring IADLs, the pooled result showed that higher numbers of IADLs were associated with decreased SM utilization (pooled OR: 0.79, 95\% CI: 0.64-0.98). Three studies measuring IADL limitations in conjunction with ADL limitations found inverse associations. ${ }^{32,59,69}$ Pooled results indicated that ADL limitations or IADL dependency led to decreased SM utilization (pooled OR: 0.72, 95\% CI: 0.57-0.91).
In jackknife analyses, removal of Schootman et al longterm ADLs and long-term IADLs and Caban et al findings led to study heterogeneity in $\mathrm{ADL}(P=0.674)$, IADL $(P=0.106)$ and ADL/IADL $(P=0.683)$ groups, respectively, being no longer statistically significant. However, the pooled estimate still had significant study heterogeneity and did not change appreciably despite removal of these studies $(P=0.003)$. Meta-regression analyses found no significant predictors of study heterogeneity.

\section{Estimates of the effect of health status, life expectancy or prognosis on utilization of SM}

Nine studies measured the association of health status on screening utilization, with eight studies measuring perceived general health $29,32,39,46,60,61,69$ and two studies measuring health status using the Short Form-12 (SF-12) survey (Table S5). ${ }^{17,27}$ The pooled result shown in Figure 4 demonstrated that lower perceived health was associated with lower SM utilization (pooled OR: 0.80, 95\% CI: 0.69-0.93). Jackknife analyses showed no significant decrease in study heterogeneity, and meta-regression analyses did not find significant predictors of study heterogeneity.

Five studies measured prognostic index or life expectancy measures against utilization of SM (Table S4)..$^{31,46,60,63,68}$ 


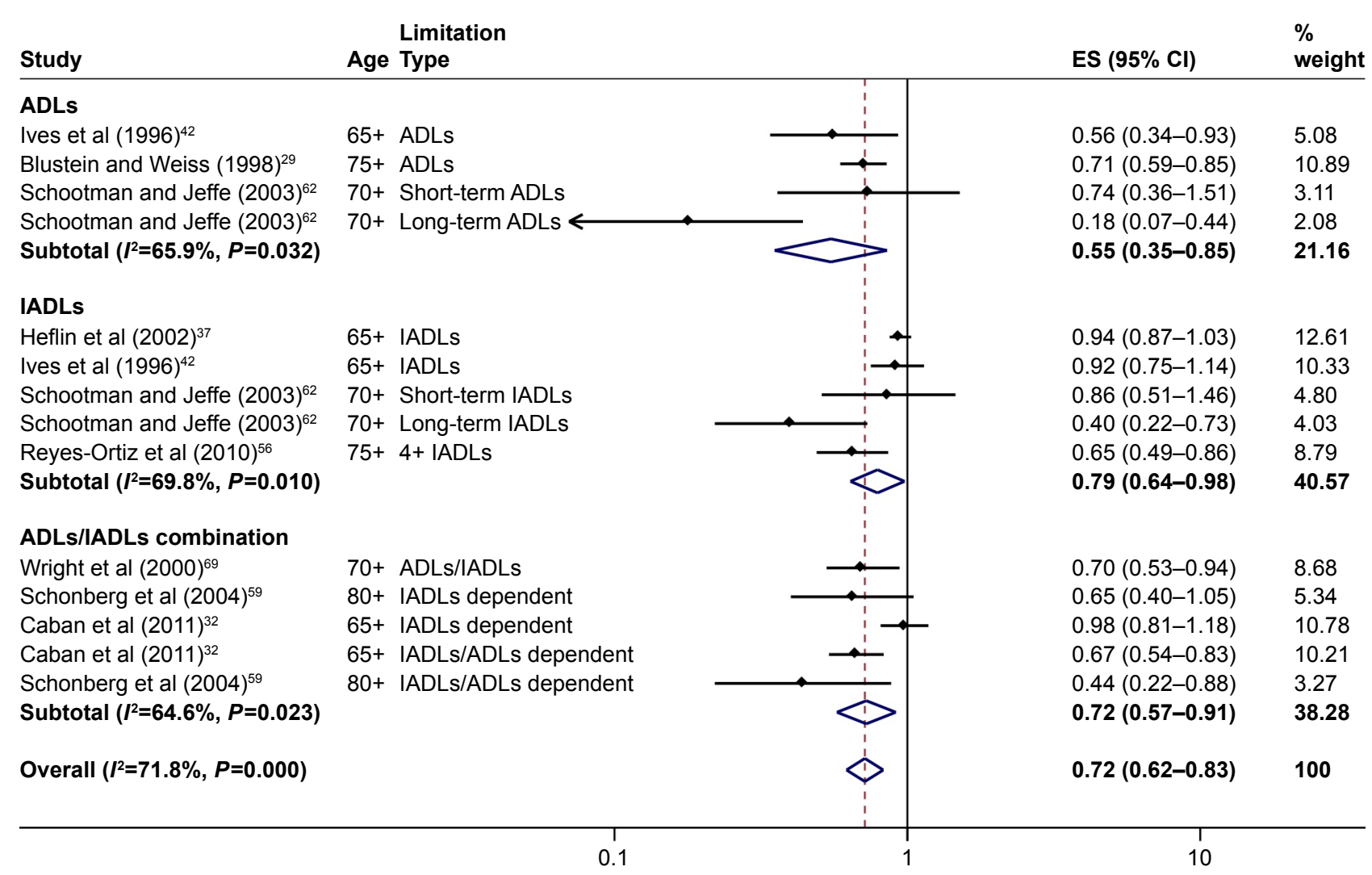

Figure 3 Forest plot of effect of functional limitations on SM utilization by study and measure type.

Note: Weights are from random-effects analysis.

Abbreviations: SM, screening mammography; ES, effect size; ADLs, activities of daily living; IADLs, instrumental activities of daily living.

The pooled effect of the three studies shown in Figure 4 measuring life expectancy using regression showed a nonsignificant inverse association between life expectancy index score and SM utilization (pooled OR: 0.73, 95\% CI: 0.53-1.00).

\section{Discussion}

Meta-analysis of the studies addressing life expectancy factors and SM utilization revealed that older American women with higher numbers of functional limitations, higher CCI score and lower perceived health are less likely to undergo routine SM. Prognostic indices, absolute number of comorbidities and specific disease conditions were not significantly associated with SM utilization. These observational studies provide a means to understanding how different measures of life expectancy affect SM utilization.

While increased CCI score was associated with a decrease in SM, the absolute number of comorbidities showed a conflicting, weak positive association with SM utilization. It is possible that having more comorbid conditions increased women's contact with their health care provider, leading to a greater likelihood of using preventive care. ${ }^{32,37}$ Conversely, one study measuring CCI showed no indication that physicians had advocated for cancer screening in the population of individuals with diabetes. ${ }^{51}$ Other studies noted that there is little time in the primary care clinic to estimate each individual's candidacy for screening, especially older patients with multiple medical problems, which might lead physicians to screen everyone to avoid confusion with recommendations or medicolegal consequences. ${ }^{17,37,59}$ The conflicting results show that more studies need to be conducted to determine who should receive SM and how comorbidity burden should factor into a provider's assessment of who is eligible for SM.

Studies consistently indicated that greater numbers of functional limitations decreased SM utilization. ${ }^{29,32,37,42,56,59,62,69}$ Studies using scales incorporating ADL limitations (ie, needing help with activities such as showering, dressing, getting in and out of bed/chairs, etc.) showed particular pronounced effects, ${ }^{29,42,62}$ which one study suggested could indicate that access factors, such as fewer resources and social supports to facilitate travel to mammography facilities, may lead to lower utilization rates. ${ }^{29} \mathrm{It}$ is therefore possible that women with ADL limitations may need more support to receive mammography utilization. Another study indicated that the strong association found between ADL and IADL (ie, needing help with everyday household chores, shopping and overall getting 


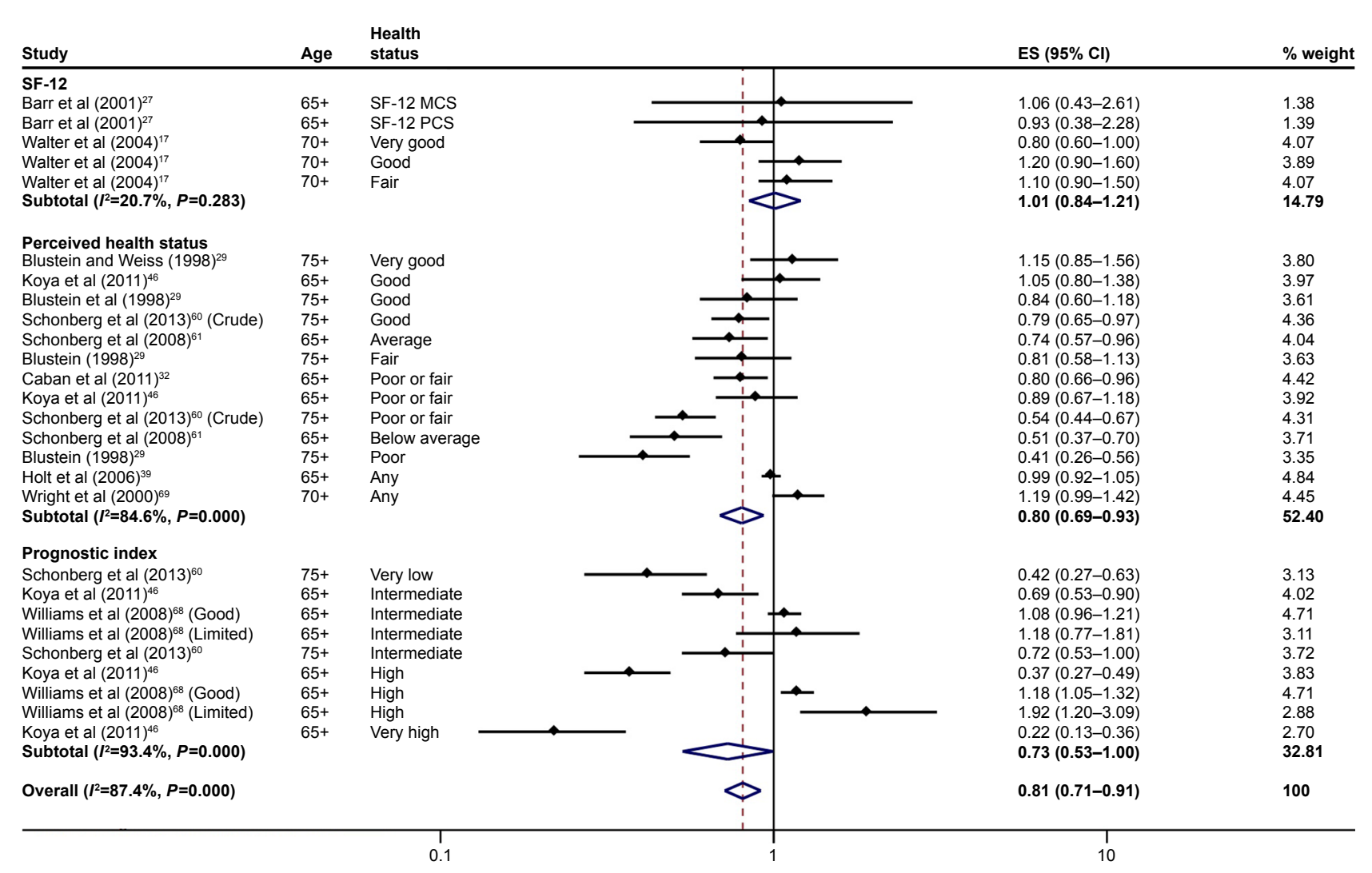

Figure 4 Forest plot of effect of health status and prognostic score on SM utilization by study and measure type.

Note: Weights are from random-effects analysis.

Abbreviations: SM, screening mammography; ES, effect size; SF-12, Short Form-12; PCS, physical component summary score; MCS, mental component summary score.

around) dependence and mammography screening might be indicative of providers considering life expectancy when referring women to $\mathrm{SM} .{ }^{69}$ However, the fact that the finding did not occur across other measured preventive screenings makes this theory questionable and requires further investigation.

Poorer self-rated health was also found to be associated with decreased screening utilization, despite some conflicting findings. In one study, pain and discomfort, a potential indicator of poorer health, was a common reason why women might decide not to screen. ${ }^{32}$ Conversely, a study done by Walter et al showed that older women with poorer health status, measured using the Medical Outcomes Study 12-item Short Form Physical Summary Scale (SF-12), did not avoid screening. Although Walter et al did not have mortality follow-up information on the sample, there is strong evidence that life expectancy is limited in women with worst health status measured by the SF-12. ${ }^{17}$

Pooled analysis of prognostic index scores found no significant association with SM utilization, even though some individual studies had significant findings. Koya et al found mammography use significantly associated with 4-year mortality risk and not age alone, attributing their finding to including age, comorbidity and functional status in their measurement of mortality risk. ${ }^{46}$ They hypothesized that the association means clinicians are skilled at identifying predictors of life expectancy in older individuals. ${ }^{46}$ However, findings from other included studies seem to contradict this theory. ${ }^{60,68}$

Findings from these studies show that functional limitations and comorbidities when measured using the CCI are associated with decreased SM utilization, while absolute number of comorbidities was weakly associated with increased screening utilization. When discussing SM with older women, providers should ask questions or consult medical records to learn more about these life expectancy factors to better assess the potential benefit older women might receive from undergoing SM. Decision aids have been developed in breast cancer screening to measure key comorbidity and functional measures, though none have been widely implemented. ${ }^{72,73}$ While more research is necessary to further understand the importance of life expectancy in measuring harms and benefits of SM, these findings indicate that providers may be weighing more than just age when discussing continuing SM with an older woman. Further assessment of current clinical recommendations and determination of eligibility for SM could lead to more accurately tailored screening referrals. 


\section{Strengths and limitations of studies and analysis}

Our systematic review/meta-analysis had key strengths, such as incorporating searches from three major research publication databases ensuring full capture of the literature on life expectancy factors and SM utilization in older women. The use of quality assessment tools allowed us to quantitatively rate the quality of the studies included in our analyses. In addition, the use of stratification to clearly review the life expectancy factors ensured a limited degree of study heterogeneity when measuring our various exposures and SM utilization. Our study also was able to leverage metaregression in sensitivity analyses to learn more about how different study features contributed to heterogeneity found in pooled results from meta-analyses.

Our review also had several limitations. The 20-year timespan of systematic review could lead to varied results due to secular trends, but examining the study results by year does not indicate that a trend exists. While this might account for some variation in the results, the lack of significant changes in screening mammography guidelines or public outreach within this older age group make any difference in effects due to secular trends minimal. Of the 25 studies included in our analysis, 17 relied on self-reported information for measurement of the exposure, while 16 relied on self-reported information to measure SM utilization. This raises concerns about recall bias, particularly when citing screening utilization within the last $2-5$ years. Furthermore, self-reported health status is not a precise measurement of an individual's health, as it uses a Likert scale to assess health at the instance of interview, which might not represent an individual's overall health outside the clinical environment. Studies that ascertained screening

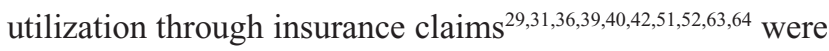
unable to distinguish between mammograms undertaken for screening and diagnostic purposes. However, it is reasonable from a clinical perspective to assume that the majority were screening procedures, since diagnostic procedures are performed only when a woman presents with symptoms of breast cancer. ${ }^{29,51,52}$ The inability to distinguish the two types of mammography might lead to the measured population being slightly sicker than the normal SM population, which would lead to an overestimate of association.

More than half of the studies included were crosssectional by design, which restricts the ability to ensure temporality of the exposure/outcome relationship. Despite this concern, all but two studies were of moderate to excellent study quality based on our cross-sectional study-specific quality assessment using the Newcastle-Ottawa Survey.

\section{Conclusion}

Studies have shown that the primary determinant of screening with mammography, regardless of age, is a physician's recommendation..$^{59,74-76}$ It is therefore critical that the guidelines be updated to reflect the importance of characteristics such as the presence of severe functional dependencies in ADLs and severe comorbidity as caused by conditions such as end-stage renal disease and severe dementia in concert with clinical judgment to estimate an individual's potential risks and benefits from screening rather than basing screening decisions on age alone. This systematic review and meta-analysis shows that consideration of functional status and comorbidity might be occurring in practice but still needs to be further weighed in SM recommendations, and targeted interventions are needed to facilitate precision cancer screening.

\section{Data availability statement}

The datasets used and/or analyzed during the current study are available from the corresponding author on reasonable request.

\section{Acknowledgments}

We thank Min-Lin Fang, MLS, and Gloria Won, MLS, for their assistance with the literature search. This research was supported by Grant No 121891-MRSG-12-007-01-CPHPS from the American Cancer Society (to Dr Braithwaite) and Grant No 1R01CA207361-01A1 from the National Cancer Institute (to Dr Braithwaite). We certify that this work is confirmatory of epidemiologic research into SM use in older women (references included in Table 1). This review systematically examines the current evidence that exists about SM recommendations in older women incorporate life expectancy factors. The sponsors of the research, the American Cancer Society and National Cancer Institute, only provided funding for the project, but did not provide any additional contribution to the project.

\section{Author contributions}

JD and DB contributed toward concept and design. JD, TA and $\mathrm{DB}$ were involved in review and quality assessment of literature. JD, TA, IA, TO, RAH and DB performed analysis and interpretation of the data. JD, TA, IA, TO, RAH and DB carried out drafting of manuscript. JD, TA, IA, TO, RAH and DB contributed toward critical revision of the manuscript for important intellectual content. JD, IA and DB performed statistical analysis. DB obtained funding. JD, TA, IA, TO, RAH and DB agree to be accountable for all aspects of the work. All authors contributed to data analysis, drafting and revising 
the article, gave final approval of the version to be published, and agree to be accountable for all aspects of the work.

\section{Disclosure}

The authors report no conflicts of interest in this work.

\section{References}

1. Coughlin SS, Thompson TD, Hall HI, Logan P, Uhler RJ. Breast and cervical carcinoma screening practices among women in rural and nonrural areas of the United States, 1998-1999. Cancer. 2002;94(11): 2801-2812.

2. HealthCare.gov. Preventive Health Services for Women. Available from: https://www.healthcare.gov/preventive-care-benefits/women/. Accessed April 9, 2015.

3. Smith RA, Saslow D, Sawyer KA, et al. American Cancer Society guidelines for breast cancer screening: update 2003. CA Cancer J Clin. 2003;53(3):141-169.

4. Siu Al US. Preventive Services Task Force. Screening for Breast Cancer: U.S. Preventive Services Task Force Recommendation Statement. Ann Intern Med. 2016;164(4):279-296.

5. Randolph WM, Goodwin JS, Mahnken JD, Freeman JL. Regular mammography use is associated with elimination of age-related disparities in size and stage of breast cancer at diagnosis. Ann Intern Med. 2002; 137(10):783-790.

6. Kerlikowske K. Evidence-based breast cancer prevention: the importance of individual risk. Ann Intern Med. 2009;151(10):750.

7. Walter LC, Schonberg MA. Screening mammography in older women: a review. JAMA. 2014;311(13):1336-1347.

8. Health screening decisions for older adults: AGS position paper. $J \mathrm{Am}$ Geriatr Soc. 2003;51(2):270-271.

9. Cruz M, Covinsky K, Widera EW, Stijacic-Cenzer I, Lee SJ. Predicting 10-year mortality for older adults. JAMA. 2013;309(9):874-876.

10. Walter LC, Covinsky KE. Cancer screening in elderly patients: a framework for individualized decision making. JAMA. 2001;285(21): 2750-2756.

11. Mossey JM, Shapiro E. Self-rated health: a predictor of mortality among the elderly. Am J Public Health. 1982;72(8):800-808.

12. Reuben DB, Siu AL, Kimpau S. The predictive validity of self-report and performance-based measures of function and health. $J$ Gerontol. 1992;47(4):M106-M110.

13. Scott WK, Macera CA, Cornman CB, Sharpe PA. Functional health status as a predictor of mortality in men and women over 65. J Clin Epidemiol. 1997;50(3):291-296.

14. Fried LP, Kronmal RA, Newman AB, et al. Risk factors for 5-year mortality in older adults: the Cardiovascular Health Study. JAMA. 1998;279(8):585-592.

15. Smith RA, Andrews K, Brooks D, et al. Cancer screening in the United States, 2016: A review of current American Cancer Society guidelines and current issues in cancer screening. CA Cancer J Clin. 2016;66(2): 95-114.

16. Demb J, Allen I, Braithwaite D. Utilization of screening mammography in older women according to comorbidity and age: protocol for a systematic review. Syst Rev. 2016;5(1):168.

17. Walter LC, Lindquist K, Covinsky KE. Relationship between health status and use of screening mammography and Papanicolaou smears among women older than 70 years of age. Ann Intern Med. 2004;140(9): 681-688.

18. US Preventive Services Task Force. Screening for breast cancer: U.S. Preventive Services Task Force recommendation statement. Ann Intern Med. 2009;151(10):716-726.

19. Wells G, Shea B, O'connell D, Peterson J. The Newcastle-Ottawa Scale (NOS) for Assessing the Quality of Nonrandomised Studies in Meta-Analyses; 2000. Available from: http://www.ohri.ca/programs/ clinical_epidemiology/oxford.asp. Accessed February 29, 2016.
20. Higgins JP, Altman DG, Gøtzsche PC, et al. The Cochrane Collaboration's tool for assessing risk of bias in randomised trials. BMJ. 2011; 343(oct18_2):d5928.

21. Efron B. The Jackknife, the Bootstrap and Other Resampling Plans. Society for Industrial and Applied Mathematics; 1982.

22. Egger M, Smith G, Altman DG. Systematic Reviews in Health Care: Meta-Analysis in Context. 2nd ed. London: BMJ Publishing Group; 2001.

23. Berkey CS, Hoaglin DC, Mosteller F, Colditz GA. A random-effects regression model for meta-analysis. Stat Med. 1995;14(4):395-411.

24. Thompson SG, Higgins JP. How should meta-regression analyses be undertaken and interpreted? Stat Med. 2002;21(11):1559-1573.

25. Ahmed NU, Smith GL, Haber G, Belcon MC. Are women with functional limitations at high risk of underutilization of mammography screening? Womens Health Issues. 2009;19(1):79-87.

26. Armour BS, Thierry JM, Wolf LA. State-level differences in breast and cervical cancer screening by disability status: United States, 2008. Womens Health Issues. 2009;19(6):406-414.

27. Barr JK, Reisine S, Wang Y, et al. Factors influencing mammography use among women in Medicare managed care. Health Care Financ Rev. 2001;22(4):49-61.

28. Beckman TJ, Cuddihy RM, Scheitel SM, Naessens JM, Killian JM, Pankratz VS. Screening mammogram utilization in women with diabetes. Diabetes Care. 2001;24(12):2049-2053.

29. Blustein J, Weiss LJ. The use of mammography by women aged 75 and older: factors related to health, functioning, and age. J Am Geriatr Soc. 1998;46(8):941-946.

30. Burack RC, Gurney JG, Mcdaniel AM. Health status and mammography use among older women. J Gen Intern Med. 1998;13(6): 366-372.

31. Bynum JP, Braunstein JB, Sharkey P, Haddad K, Wu AW, Aw W. The influence of health status, age, and race on screening mammography in elderly women. Arch Intern Med. 2005;165(18):2083-2088.

32. Caban M, Kuo YF, Raji M, Tan A, Freeman J. Predictors of mammography use in older women with disability: the patients' perspectives. Med Oncol. 2011;28(Suppl 1):8-14.

33. Caplan LS. To screen or not to screen: the issue of breast cancer screening in older women. Public Health Rev. 2001;29(2-4):231-240.

34. Deshpande AD, Mcqueen A, Coups EJ. Different effects of multiple health status indicators on breast and colorectal cancer screening in a nationally representative US sample. Cancer Epidemiol. 2012;36(3): 270-275.

35. Gandhi PK, Gentry WM, Kibert JL, et al. The relationship between four health-related quality-of-life indicators and use of mammography and Pap test screening in US women. Qual Life Res. 2015;24(9): 2113-2128.

36. Harrison RV, Janz NK, Wolfe RA, Tedeschi PJ, Huang X, Mcmahon LF. 5 -Year mammography rates and associated factors for older women. Cancer. 2003;97(5):1147-1155.

37. Heflin MT, Oddone EZ, Pieper CF, Burchett BM, Cohen HJ. The effect of comorbid illness on receipt of cancer screening by older people. $J$ Am Geriatr Soc. 2002;50(10):1651-1658.

38. Heflin MT, Pollak KI, Kuchibhatla MN, Branch LG, Oddone EZ. The impact of health status on physicians' intentions to offer cancer screening to older women. J Gerontol A Biol Sci Med Sci. 2006;61(8): 844-850.

39. Holt K, Franks P, Meldrum S, Fiscella K. Mammography Self-Report and Mammography Claims. Med Care. 2006;44(6):513-518.

40. Hubbard RA, O'Meara ES, Henderson LM, et al. Multilevel factors associated with long-term adherence to screening mammography in older women in the U.S. Prev Med. 2016;89:169-177.

41. Iezzoni LI, Kurtz SG, Rao SR. Trends in mammography over time for women with and without chronic disability. $J$ Womens Health. 2015; 24(7):593-601.

42. Ives DG, Lave JR, Traven ND, Schulz R, Kuller LH. Mammography and pap smear use by older rural women. Public Health Rep. 1996;111(3): $244-250$. 
43. Kagay CR, Quale C, Smith-Bindman R. Screening mammography in the American elderly. Am J Prev Med. 2006;31(2):142-149.

44. Kiefe CI, Funkhouser E, Fouad MN, May DS. Chronic disease as a barrier to breast and cervical cancer screening. J Gen Intern Med. 1998; 13(6):357-365.

45. Kim SC, Schneeweiss S, Myers JA, Liu J, Solomon DH. No differences in cancer screening rates in patients with rheumatoid arthritis compared to the general population. Arthritis Rheum. 2012;64(10):3076-3082.

46. Koya DL, Chen JG, Smith TG, Moran WP. Screening mammography use in Medicare beneficiaries reflects 4-year mortality risk. Am J Med. 2011;124(4):369.e1-36369.e1.

47. Legg JS, Clement DG, White KR. Are women with self-reported cognitive limitations at risk for underutilization of mammography? J Health Care Poor Underserved. 2004;15(4):688-702.

48. Lipscombe LL, Hux JE, Booth GL. Reduced screening mammography among women with diabetes. Arch Intern Med. 2005;165(18): 2090-2095.

49. Mandelblatt JS, Wheat ME, Monane M, Moshief RD, Hollenberg JP, Tang J. Breast cancer screening for elderly women with and without comorbid conditions. A decision analysis model. Ann Intern Med. 1992; 116(9):722-730.

50. Mayer JA, Slymen DJ, Drew JA, Wright BL, Elder JP, Williams SJ. Breast and cervical cancer screening in older women: the San Diego Medicare Preventive Health Project. Prev Med. 1992;21(4):395-404.

51. Mcbean AM, Yu X. The underuse of screening services among elderly women with diabetes. Diabetes Care. 2007;30(6):1466-1472.

52. Mehta KM, Fung KZ, Kistler CE, Chang A, Walter LC. Impact of cognitive impairment on screening mammography use in older US women. Am J Public Health. 2010;100(10):1917-1923.

53. Messecar DC. Mammography screening for older women with and without cognitive impairment. J Gerontol Nurs. 2000;26(4):14-24.

54. Parish SL, Swaine JG, Son E, Luken K. Receipt of mammography among women with intellectual disabilities: medical record data indicate substantial disparities for African American women. Disabil Health J. 2013;6(1):36-42.

55. Persky NW, Burack R. Predictors of mammography use in the past year among elderly women. J Aging Health. 1997;9(3):334-354.

56. Reyes-Ortiz CA, Markides KS, Factors S. Socioeconomic factors, immigration status, and cancer screening among Mexican American women aged 75 and older. Health Care Women Int. 2010;31(12):1068-1081.

57. Sanderson M, Lipworth L, Han X, et al. Mammography use among women with and without diabetes: results from the Southern Community Cohort Study. J Epidemiol Glob Health. 2014;4(3):223-230.

58. Schonberg MA, Mccarthy EP. Mammography screening among women age 80 years and older: consider the risks. J Clin Oncol. 2009; 27(4):640-641.

59. Schonberg MA, Mccarthy EP, Davis RB, Phillips RS, Hamel MB. Breast cancer screening in women aged 80 and older: results from a national survey. J Am Geriatr Soc. 2004;52(10):1688-1695.
60. Schonberg MA, Breslau ES, Mccarthy EP. Targeting of mammography screening according to life expectancy in women aged 75 and older. J Am Geriatr Soc. 2013;61(3):388-395.

61. Schonberg MA, Leveille SG, Marcantonio ER. Preventive health care among older women: missed opportunities and poor targeting. Am J Med. 2008;121(11):974-981.

62. Schootman M, Jeffe DB. Identifying factors associated with disabilityrelated differences in breast cancer screening (United States). Cancer Causes Control. 2003;14(2):97-107.

63. Scinto JD, Gill TM, Grady JN, Holmboe ES. Screening mammography: Is it suitably targeted to older women who are most likely to benefit? J Am Geriatr Soc. 2001;49(8):1101-1104.

64. Tan A, Kuo YF, Goodwin JS. Integrating age and comorbidity to assess screening mammography utilization. Am J Prev Med. 2012; 42(3):229-234.

65. Thorpe JM, Kalinowski CT, Patterson ME, Sleath BL. Psychological distress as a barrier to preventive care in community-dwelling elderly in the United States. Med Care. 2006;44(2):187-191.

66. Tishler J, Mccarthy EP, Rind DM, Hamel MB. Breast cancer screening for older women in a primary care practice. J Am Geriatr Soc. 2000;48(8): 961-966.

67. Vacek PM, Skelly JM. A prospective study of the use and effects of screening mammography in women aged 70 and older. J Am Geriatr Soc. 2015;63(1):1-7.

68. Williams BA, Lindquist K, Sudore RL, Covinsky KE, Walter LC Screening mammography in older women. Effect of wealth and prognosis. Arch Intern Med. 2008;168(5):514-520.

69. Wright PJ, Fortinsky RH, Covinsky KE, Anderson PA, Landefeld CS. Delivery of preventive services to older black patients using neighborhood health centers. J Am Geriatr Soc. 2000;48(2):124-130.

70. Xiang X. Serious psychological distress as a barrier to cancer screening among women. Womens Health Issues. 2015;25(1):49-55.

71. Wu ZH, Black SA, Markides KS. Prevalence and associated factors of cancer screening: why are so many older Mexican American women never screened? Prev Med. 2001;33(4):268-273.

72. Yourman LC, Lee SJ, Schonberg MA, Widera EW, Smith AK. Prognostic Indices for Older Adults. JAMA. 2012;307(2):182.

73. Schonberg MA, Hamel MB, Davis RB, et al. Development and evaluation of a decision aid on mammography screening for women 75 years and older. JAMA Intern Med. 2014;174(3):417-424.

74. Zapka JG, Stoddard A, Maul L, Costanza ME. Interval adherence to mammography screening guidelines. Med Care. 1991;29(8):697-707.

75. Fox SA, Murata PJ, Stein JA. The impact of physician compliance on screening mammography for older women. Arch Intern Med. 1991; 151(1):50-56.

76. Grady KE, Lemkau JP, Mcvay JM, Reisine ST. The importance of physician encouragement in breast cancer screening of older women. Prev Med. 1992;21(6):766-780.
Clinical Interventions in Aging

\section{Publish your work in this journal}

Clinical Interventions in Aging is an international, peer-reviewed journal focusing on evidence-based reports on the value or lack thereof of treatments intended to prevent or delay the onset of maladaptive correlates of aging in human beings. This journal is indexed on PubMed Central, MedLine,

\section{Dovepress}

CAS, Scopus and the Elsevier Bibliographic databases. The manuscript management system is completely online and includes a very quick and fair peer-review system, which is all easy to use. Visit http://www.dovepress. com/testimonials.php to read real quotes from published authors. 